Supporting Information 


\title{
Micro-pseudocapacitors with Electroactive Polymer Electrodes: Towards Ac-Line Filtering Applications
}

\author{
Narendra Kurra ${ }^{+}$, Qiu Jiang ${ }^{+}$, Ahad Syed, Chuan Xia and Husam N Alshareef* \\ Materials Science and Engineering, King Abdullah University of Science and Technology \\ (KAUST), Thuwal 23955-6900 \\ ${ }^{+}$contributed equally to the work \\ E-mail: husam.alshareef@kaust.edu.sa
}

\section{Supporting Information}

Areal cell capacitance $\left(\mathrm{C}_{\text {cell }}\right)$ was calculated from the charge-discharge curves according to the following equations.

Cell capacitance $\left(\mathrm{C}_{\text {cell }}\right)=\left(\mathrm{i} / \mathrm{A}_{\mathrm{two}}\right)(\Delta \mathrm{t} / \Delta \mathrm{E}) \quad$ (for 2-electrode configuration $)$.

Where $A_{t w o}$ is the total area of both the electrodes, ' $\mathrm{i}$ ' is the applied current, $\Delta \mathrm{t}$ is the discharge time and $\Delta \mathrm{E}$ is the potential window.

Volumetric capacitance $\left(\mathrm{C}_{\mathrm{vol}}\right)=\left(\mathrm{i} / \mathrm{v}_{\mathrm{t}}\right)(\Delta \mathrm{t} / \Delta \mathrm{E})$

$\mathrm{C}_{\text {cell }}$ is the cell capacitance, $\mathrm{C}_{\mathrm{vol}}$ is the volumetric capacitance, $\mathrm{v}_{\mathrm{t}}$ is the total volume of both the electrodes.

Resistor-capacitor, RC time constants $\left(\tau_{\mathrm{RC}}\right)$ at each frequency were calculated using the formula:

$$
\tau_{\mathrm{RC}}=\mathrm{Z}^{\prime} /\left(2 \pi \mathrm{fZ} \mathrm{Z}^{\prime \prime}\right)
$$

where $Z^{\prime}$ and $Z^{\prime \prime}$ are the real and imaginary components of impedance, $f$ is the frequency.

The real $\left(\mathrm{C}^{\prime}\right)$ and imaginary $\left(\mathrm{C}^{\prime \prime}\right)$ parts of capacitances were calculated using the following fomulae. 
$C^{\prime}=-Z^{\prime \prime} /\left(2 \pi f A_{t w o}|Z|^{2}\right)$

$\mathrm{C}^{\prime \prime}=\mathrm{Z}^{\prime} /\left(2 \pi \mathrm{f} \mathrm{A}_{\mathrm{two}}|\mathrm{Z}|^{2}\right)$

Where $|\mathrm{Z}|$ is the absolute value of impedance.

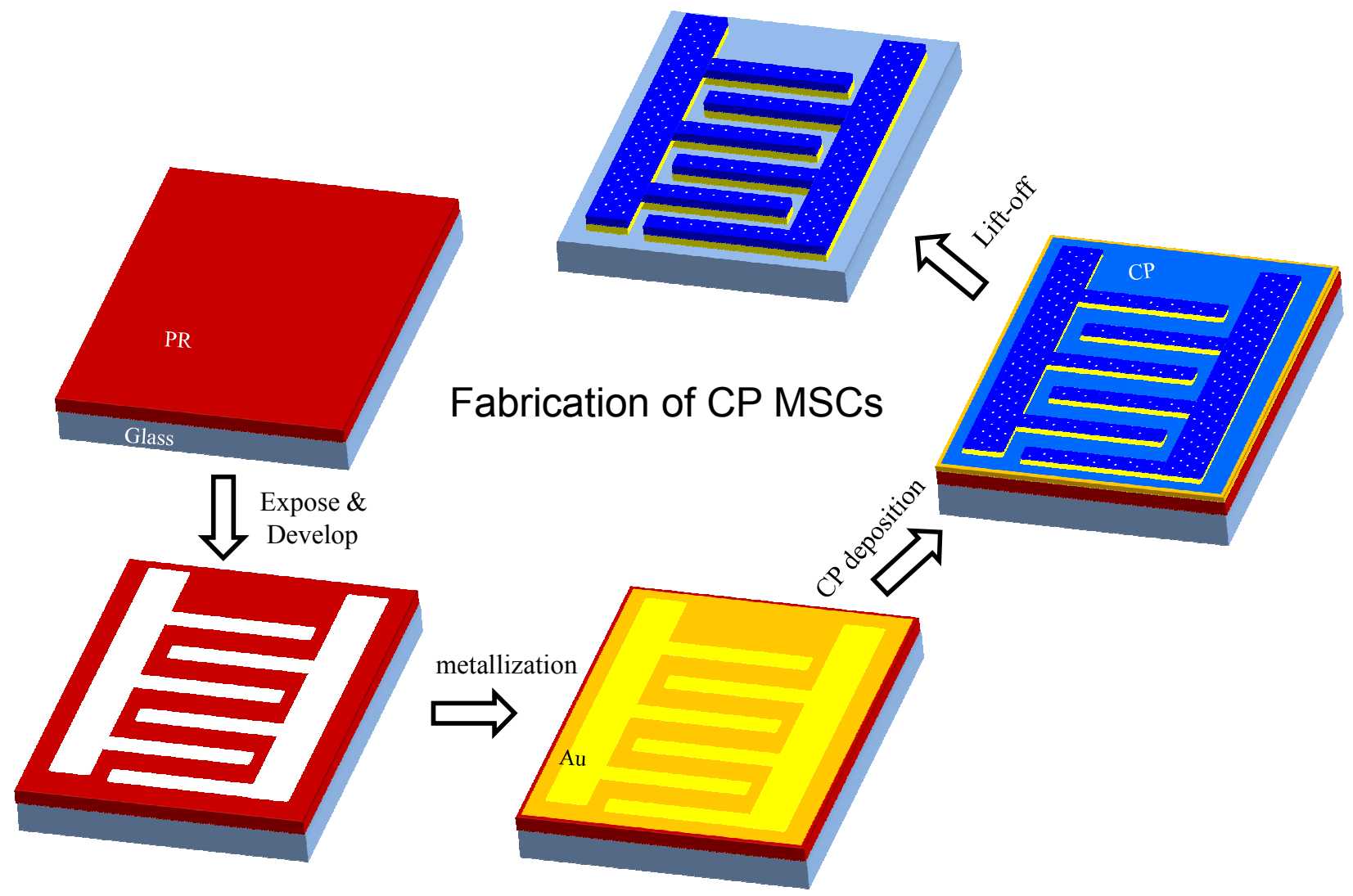

Figure S1. Schematic illustration of fabrication of conducting polymer micro-pseudocapacitors (MPCs). 

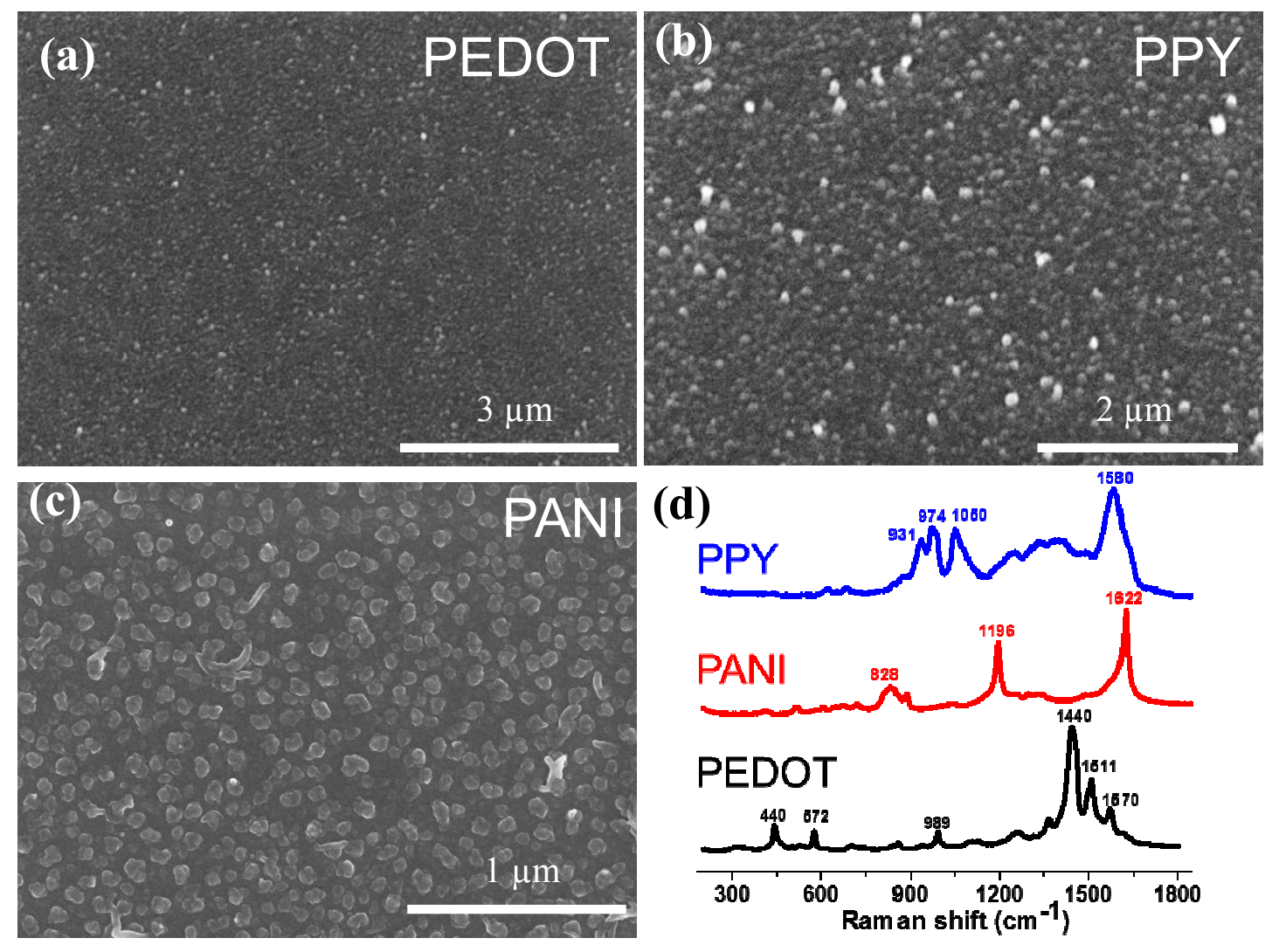

Figure S2. SEM micrographs of electrodeposited (a) PEDOT, (b) PPY and (c) PANI thin films. (d) Raman spectra of electrodeposited CPs.

Raman spectra of the CPs can be assigned as follows. For PEDOT, the main intense peaks are observed at 1440, 1570 and $1511 \mathrm{~cm}^{-1}$, corresponding to the symmetric and asymmetric stretching of $\mathrm{C}_{\alpha}=C_{\beta}$. The band at $989 \mathrm{~cm}^{-1}$ corresponds to $\mathrm{C}-\mathrm{C}$ anti-symmetrical stretching mode. While the peak at $573 \mathrm{~cm}^{-1}$ is due to oxyethylene ring deformation and $440 \mathrm{~cm}^{-1}$, corresponds to $\mathrm{SO}_{2}$ bending. ${ }^{1}$ In the case of PANI, $\mathrm{C}=\mathrm{C}$ stretching vibrations yield the main peak at $1622 \mathrm{~cm}^{-1}, 1196$ and $828 \mathrm{~cm}^{-1}$ can be assigned to benzene ring deformations and $\mathrm{C}-\mathrm{H}$ deformation, respectively. ${ }^{2}$ In case of PPY, $1580 \mathrm{~cm}^{-1}$ peak corresponds to $\mathrm{C}=\mathrm{C}$ backbone stretching. 931 and $974 \mathrm{~cm}^{-1}$ peaks are attributed to ring deformation associated with bipolaron and polaron, respectively. $1050 \mathrm{~cm}^{-1}$ band corresponds to $\mathrm{C}-\mathrm{H}$ in plane bending vibration. ${ }^{3}$ 

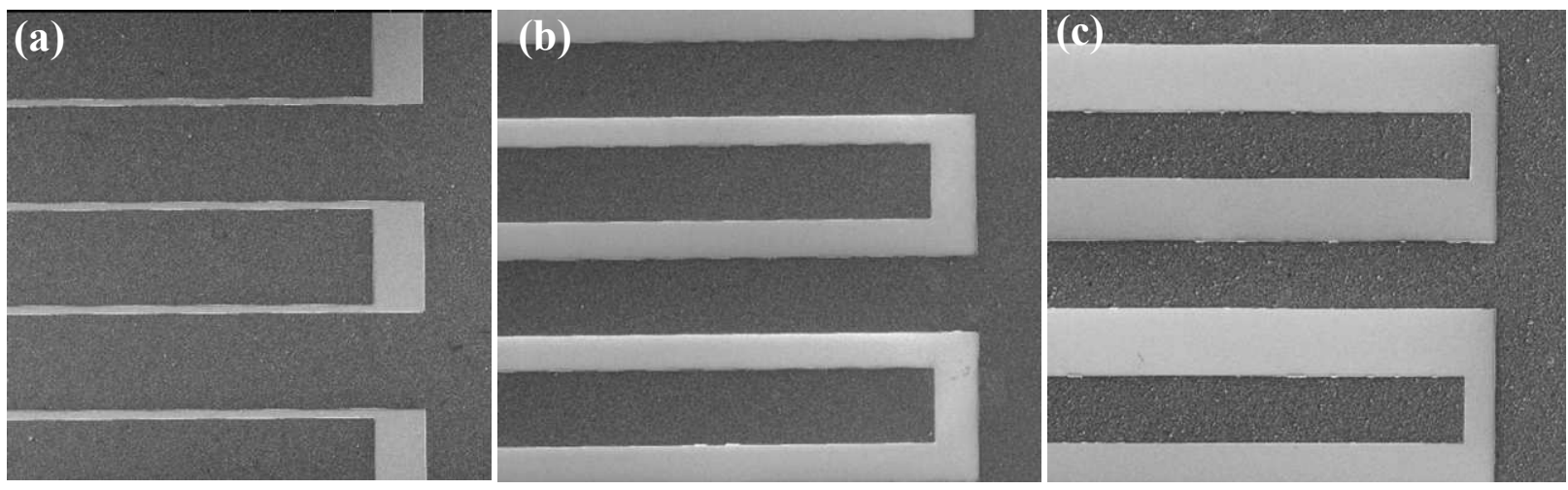

Figure S3. SEM micrographs of PEDOT MPCs with interspacing of (a) 10, (b) 50 and (c) 100 $\mu \mathrm{m}$, finger width of $100 \mu \mathrm{m}$ is same throughout.
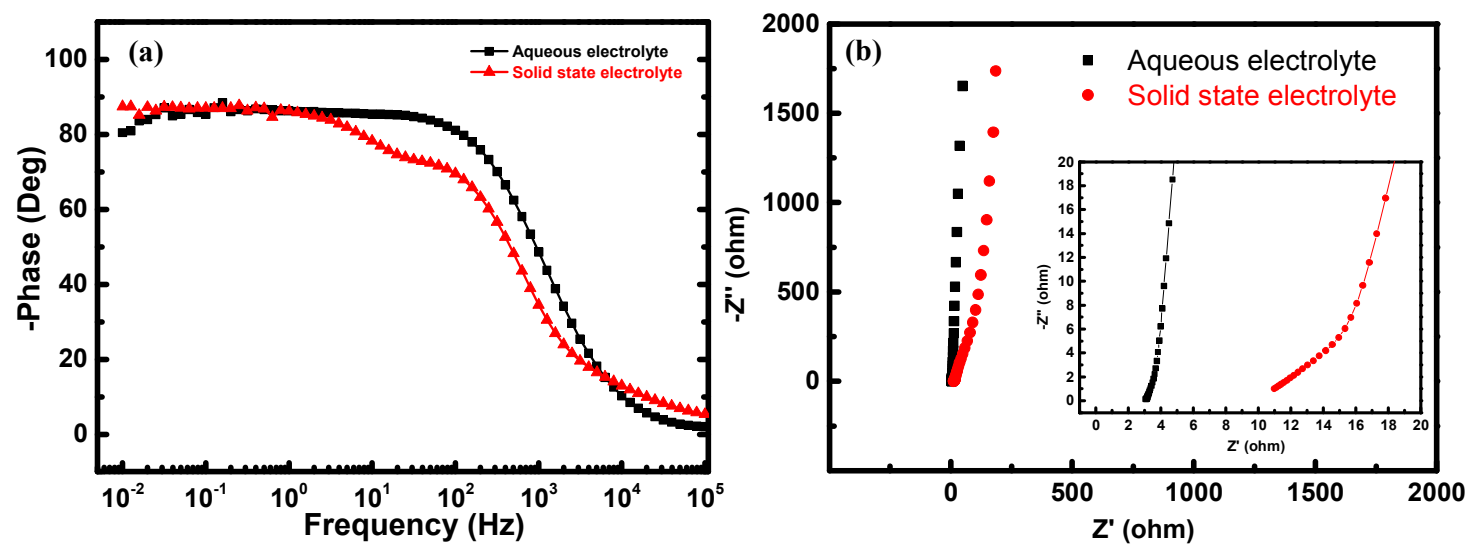

Figure S4. Comparison of (a) Bode phase angle vs. frequency and (b) Nyquist spectra of PEDOT MPCs with aqueous (black curve) and solid state (red curve) electrolytes. 


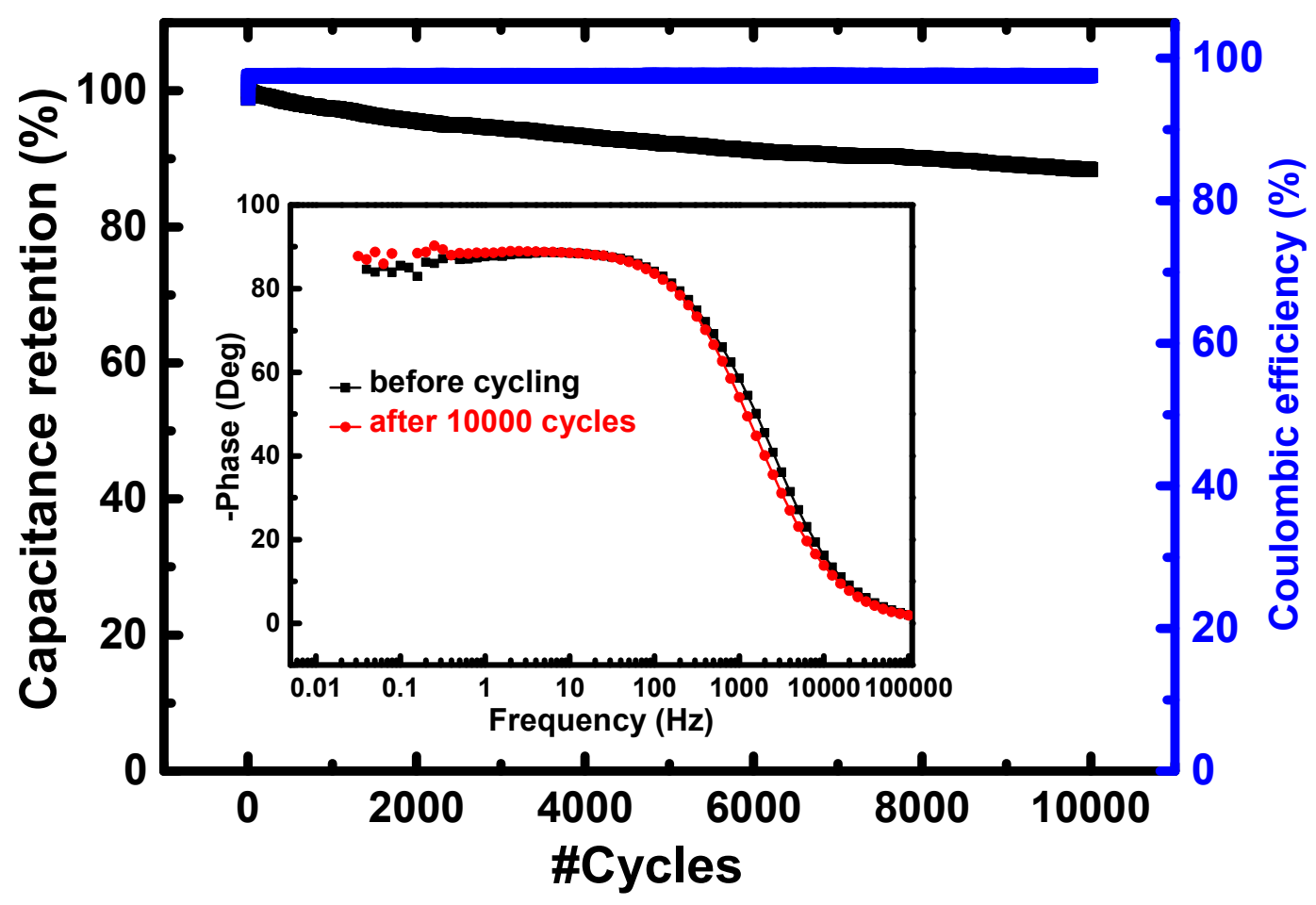

Figure S5. Cycling stability and coulombic efficiency of PEDOT MPC over 10000 cycles at a current density of $0.15 \mathrm{~mA} / \mathrm{cm}^{2}$ in $1 \mathrm{M} \mathrm{H}_{2} \mathrm{SO}_{4}$, inset shows the frequency response before and after cycling. 


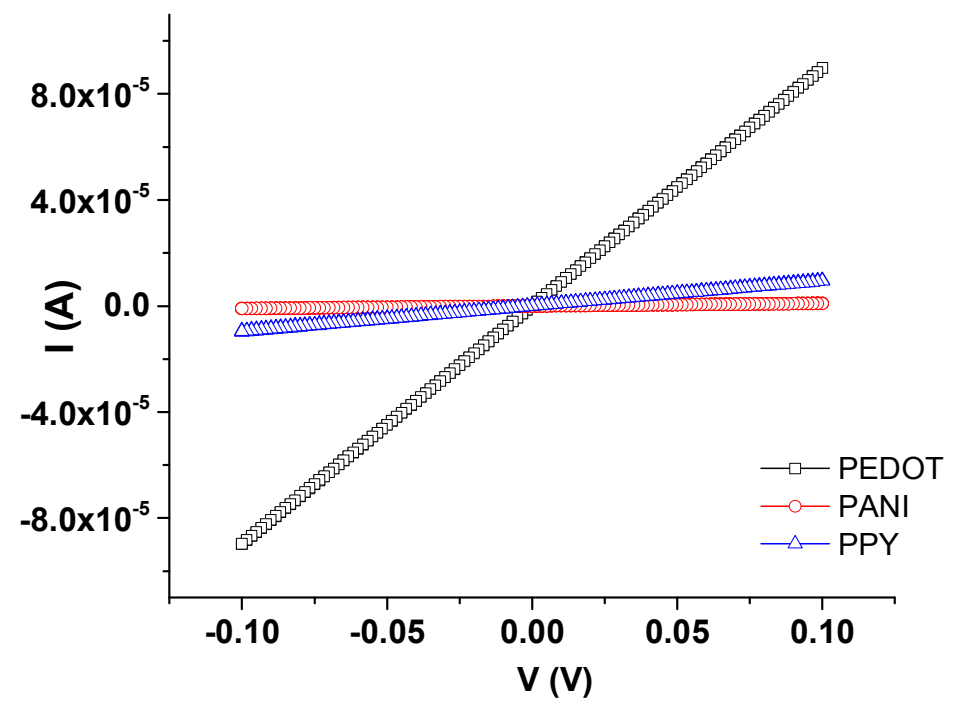

Figure S6. Four probe current-voltage characteristics of conducting polymer thin films. Typical conductivities of PEDOT, PPY and PANI thin films (thickness of $100 \mathrm{~nm}$ ) are found to be 108 , 9.2 and $2.9 \mathrm{~S} / \mathrm{cm}$, respectively.
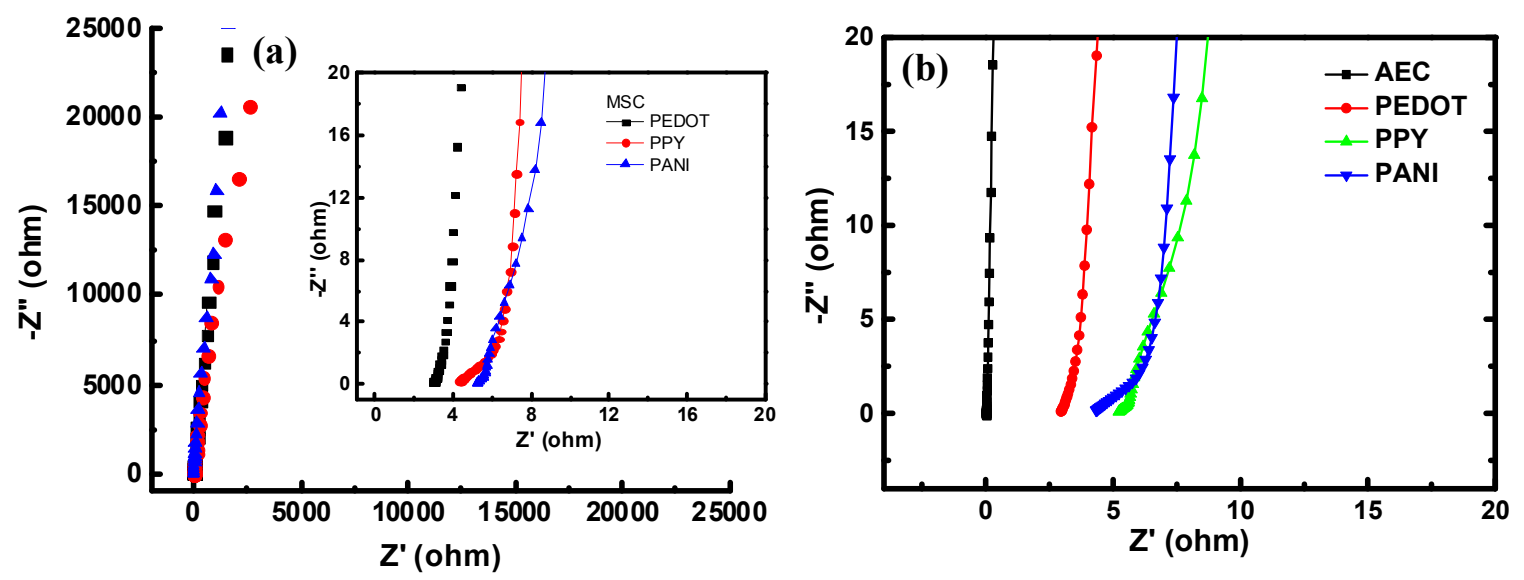

Figure S7. (a) Nyquist spectra of PEDOT, PPY and PANI MPCs (active layer thickness, $100 \mathrm{~nm}$ ), inset shows the high frequency region of the spectra. (b) Comparison of Nyquist spectra of conducting polymer micro-electrochemical capacitors with AEC. 
(a)
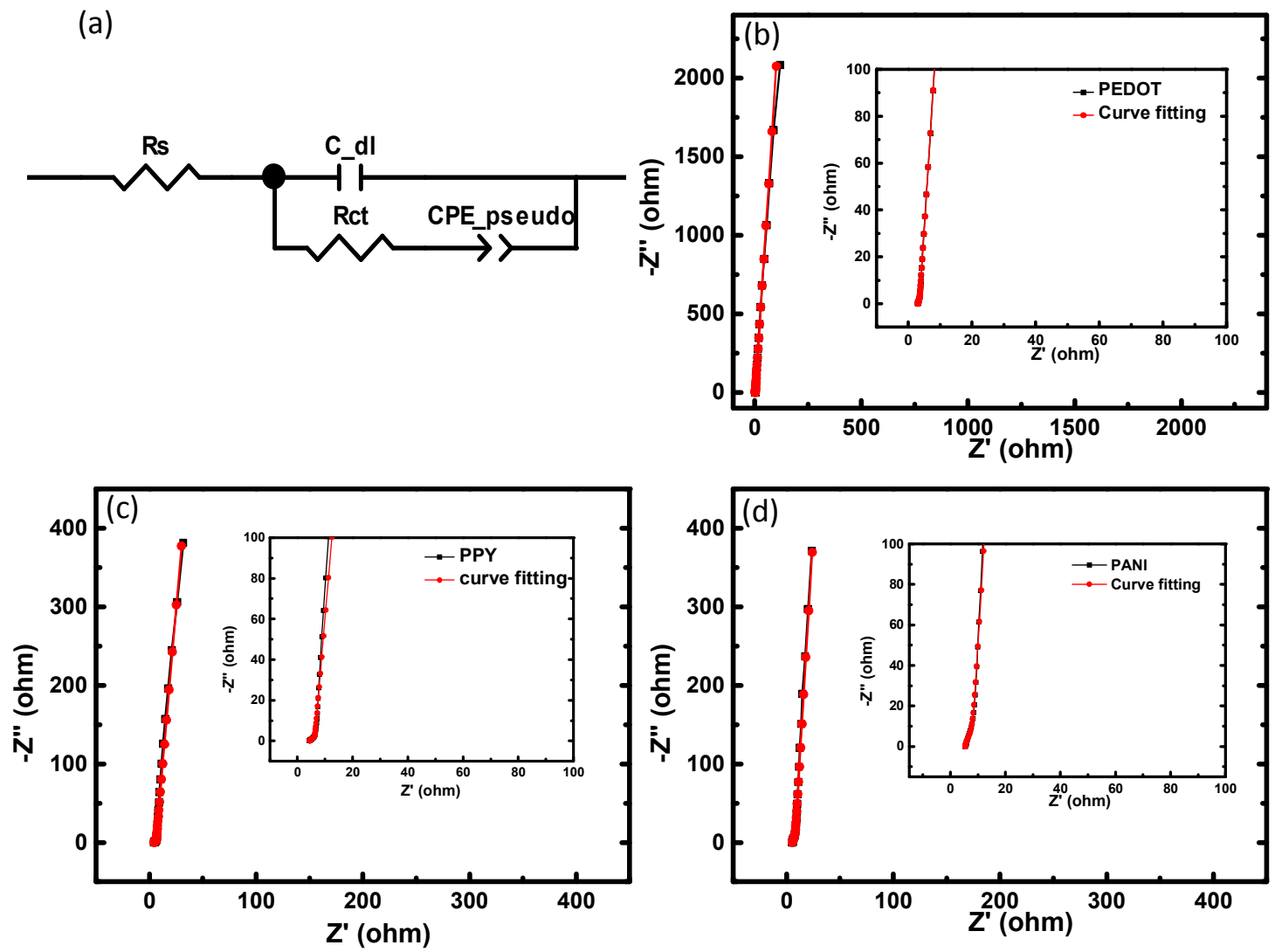

Figure S8. (a) Equivalent circuit model for fitting the impedance data of conducting polymer microsupercapacitors. Nyquist plots and fitted plot for PEDOT (b), PPY (c), PANI (d).

According to Conway, the equivalent circuit model shown in Figure S8a can be used to describe the electrochemical impedance behavior of the polymers. Constant phase element is used in the circuit because it can fit better for the rough surface of materials those used here. In the model, $\mathrm{R}_{\mathrm{s}}$ means electrolyte resistance and Rct represents charge transfer resistance. $\mathrm{C}_{\mathrm{dl}}$ and CPE_pseudo represent double layer contributed from non-faradaic charging and pseudo capacitance contributed from faradaic interfacial redox reaction. As shown in the fitted the data from Figure S8 (a), (b) and (c), the model can describe the impedance data properly with chisquared distribution of less than $10^{-4}$. From the calculation, the contribution of pseudo 
capacitance to the whole capacitance for PEDOT, PPY and PANI are $40 \%, 50 \%$ and $80 \%$, respectively.

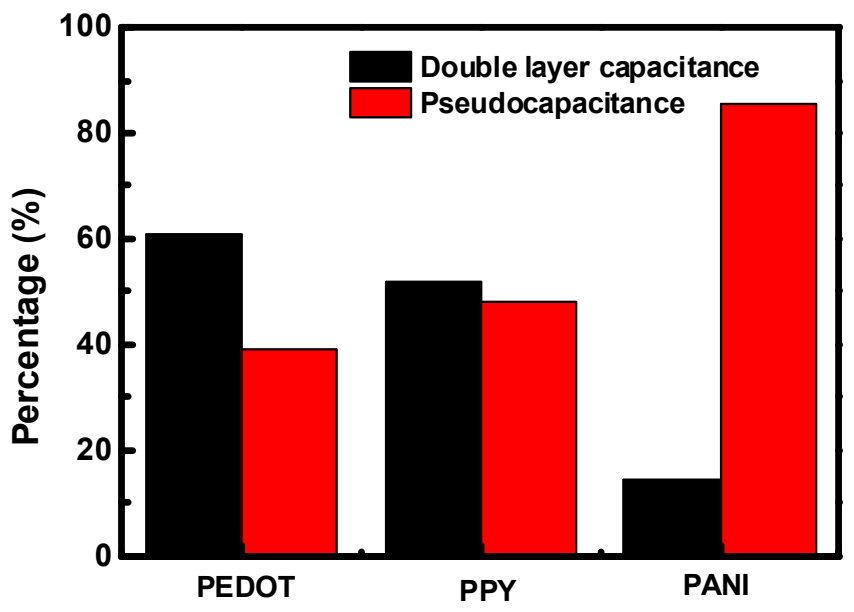

Figure S9. Percentage contribution of double layer and pseudocapacitive contributions for the conducting polymer microsupercapacitors, obtained after fitting the impedance data to an equivalent circuit shown in Figure S8.
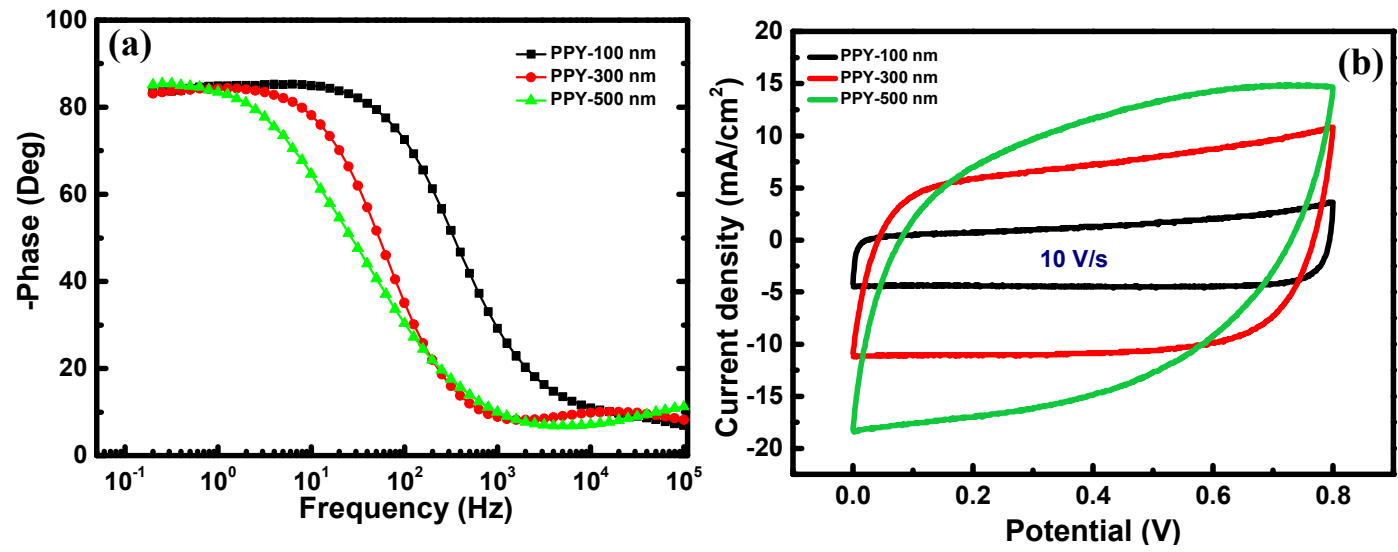

Figure S10. (a) Bode phase angle plots and (b) CVs of PPY MPCs with different thicknesses. 

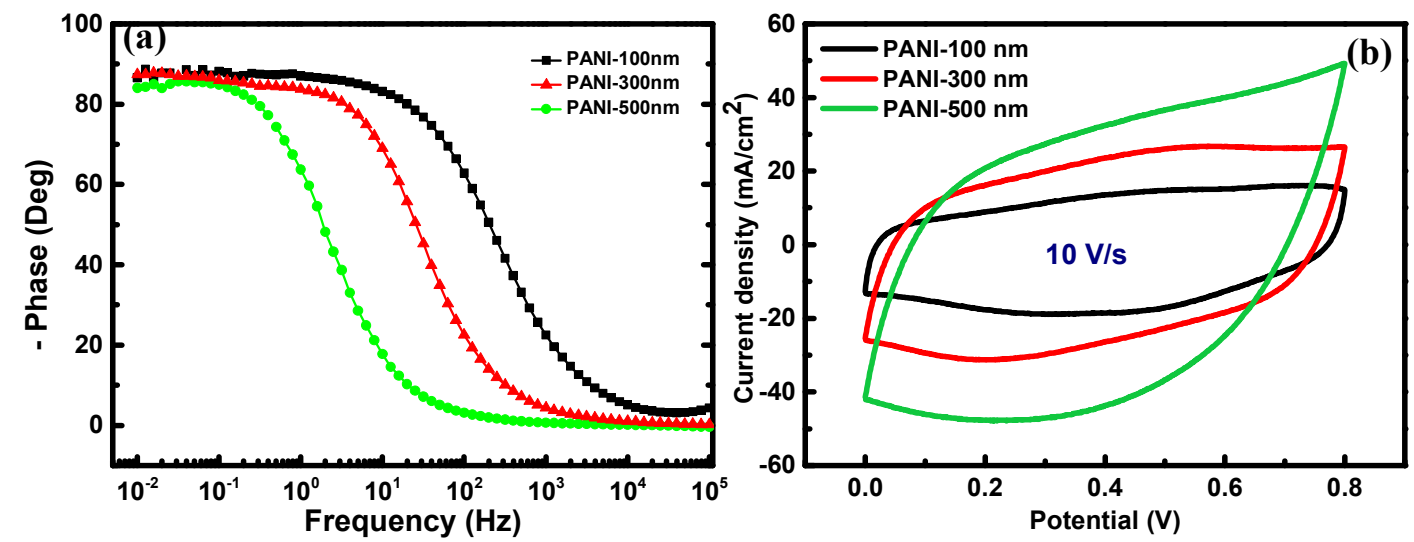

Figure S11. (a) Bode phase angle plots and (b) CVs of PANI MPCs with different thicknesses. 


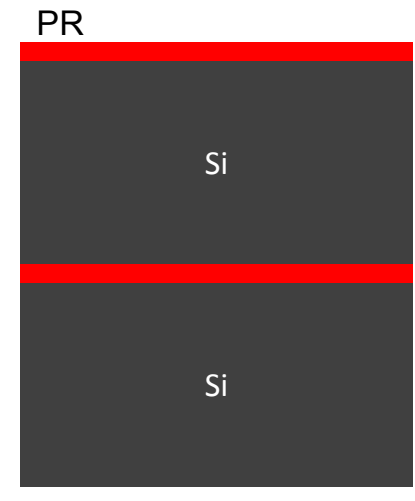

Expose

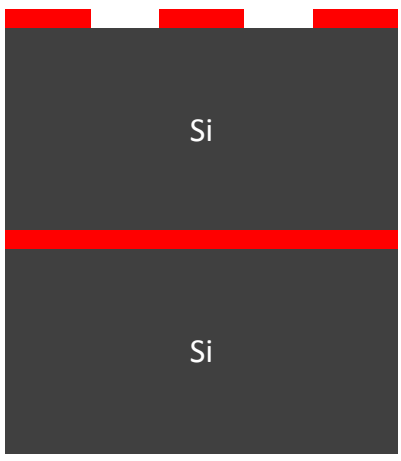

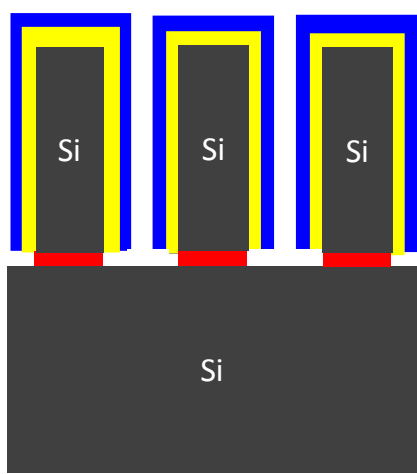
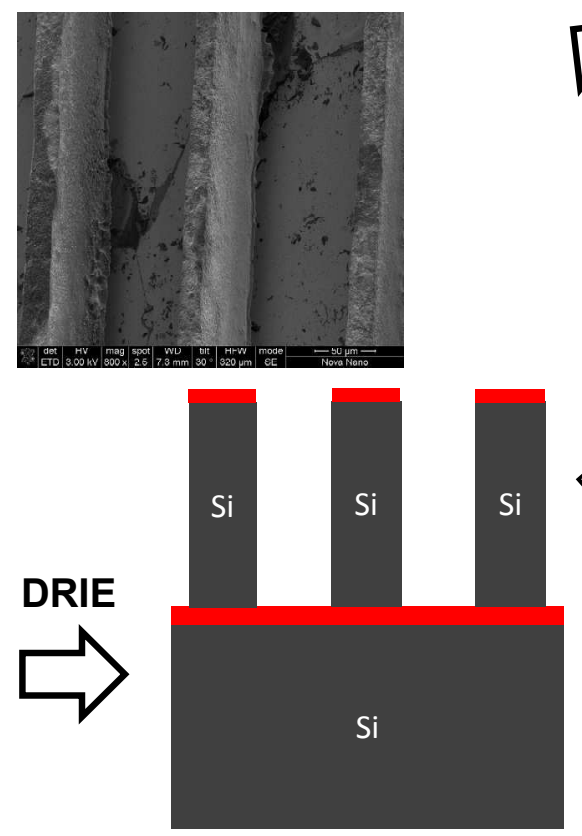
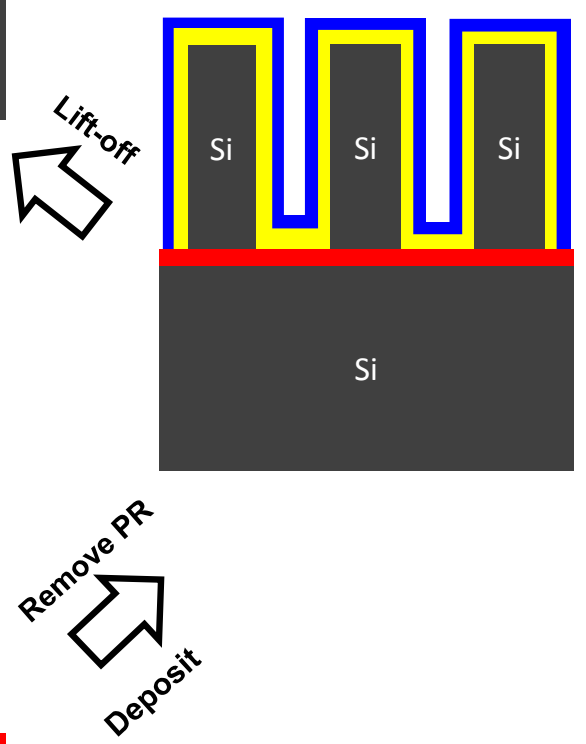

Figure S12. Schematic illustration of Si etch-through process employing photolithography and DRIE. Inset shows micrograph of interdigitated 3D Si wall structures.

DRIE is an effective process in fabricating $\mathrm{Si}$ based 3D structures in $\mathrm{Si}^{14,15}$ Two bulk $\mathrm{Si}$ substrates were bonded together by the photoresist layer. Further, the top Si wafer was coated again with the same photoresist followed by exposure through the etch mask at a constant dose of $1800 \mathrm{~mJ} / \mathrm{cm}^{2}$. The resist was develpoed using AZ726 developer to remove the exposed regions of the photoresist and gain access to the Si regions to be etched away by deep reactive ion etching (DRIE). The entire thickness of Si wafer was "etch-through" to obtain interdigitated 3D Si fingers. ${ }^{14,15}$ The DRIE was done for a total of 1400 cycles to etch through the silicon and 
stop at the photoresist used for bonding with the bottom Si wafer. The top photoresist present over the 3D Si wall structures was washed using acetone by holding the sample in the vertical position. Further, the 3D interdigitated $\mathrm{Si}$ wall structures were metallised by sputtering $250 \mathrm{~nm}$ $\mathrm{Au} / 20 \mathrm{~nm}$ Ti. Metal layers deposited over the photoresist present in the interspaces was removed by mild washing in acetone. This final step has resulted in the formation of $3 \mathrm{D} \mathrm{Au} / \mathrm{Si}$ interdigitated wall structures. 
Table S1. Comparison of electrochemical performance of micro-electrochemical capacitors (based on carbonaceous materials) reported in the literature.

\begin{tabular}{|c|c|c|c|c|c|c|c|c|c|}
\hline Reference & Electrode & Configuration & $\begin{array}{l}-\Phi @ \\
120 \mathrm{~Hz}\end{array}$ & $f @-45^{\circ}$ & $\mathbf{t}_{\mathrm{RC}}(\mathrm{ms})$ & $t_{0}(m s)$ & $\begin{array}{l}\mathrm{S}_{\max } \\
(\mathrm{V} / \mathbf{s})\end{array}$ & $\underset{\left(\mathbf{m F} / \mathbf{c m}^{2}\right)}{\mathrm{C}_{\mathrm{A}}}$ & $\begin{array}{c}\mathrm{C}_{\mathrm{V}} \\
\left(\mathbf{F} / \mathrm{cm}^{3}\right)\end{array}$ \\
\hline Commercial & $\begin{array}{c}\text { Aluminum } \\
\text { electrolytic } \\
\text { capacitor } \\
(100 \mu \mathrm{m})\end{array}$ & conventional & $84^{\circ}$ & 1600 & 0.14 & N/A & $>400$ & 0.3 & N/A \\
\hline Miller et al. ${ }^{4}$ & $\begin{array}{l}\text { Vertical } \\
\text { graphene/Ni } \\
(600 \mathrm{~nm})\end{array}$ & conventional & $82^{\circ}$ & 15000 & 0.2 & N/A & N/A & $<0.2$ & 3 \\
\hline $\begin{array}{l}\text { Du and pan } \\
\text { et al. } 5\end{array}$ & Carbon nanotubes & conventional & $<75^{\circ}$ & 636 & N/A & 1.5 & 1 & N/A & N/A \\
\hline Sheng et al. ${ }^{6}$ & $\begin{array}{l}\text { Electrochemically } \\
\text { reduced rGO } \\
(20 \mu \mathrm{m})\end{array}$ & conventional & $85.5^{\circ}$ & 4200 & 1.35 & 0.24 & 400 & $<1$ & 1 \\
\hline Yoo et al. ${ }^{7}$ & $\begin{array}{c}\text { Ultrathin CNT } \\
\text { film } \\
(50-300 ~ n m)\end{array}$ & conventional & $82.2^{\circ}$ & 1995 & 0.18 & 0.5 & 450 & 0.28 & 12 \\
\hline Wu et al. ${ }^{8}$ & $\begin{array}{c}\text { EG/PEDOT:PSS } \\
(25-125 \mathrm{~nm})\end{array}$ & conventional & $77^{\circ}$ & 1000 & 0.47 & 1 & 2000 & 0.2 & 348 \\
\hline EI-Kady et al. ${ }^{9}$ & $\begin{array}{l}\text { Laser scribed } \\
\text { graphene } \\
(7.6 \mu \mathrm{m})\end{array}$ & conventional & $<20^{\circ}$ & 30 & N/A & N/A & 10 & 3.67 & 1.5 \\
\hline Pech et al. ${ }^{10}$ & $\begin{array}{l}\text { Activated carbon } \\
\quad(1-2 \mu \mathrm{m})\end{array}$ & micro & $<1^{\circ}$ & $<5$ & N/A & 700 & 1 & 2.1 & 9 \\
\hline Gao et al. ${ }^{11}$ & $\begin{array}{l}\text { Laser reduced } \\
\text { graphene oxide } \\
\quad(22 \mu \mathrm{m})\end{array}$ & micro & N/A & $<5$ & N/A & N/A & $<0.1$ & 1.0 & 5 \\
\hline Pech et al. ${ }^{12}$ & $\begin{array}{l}\text { Onion like carbon } \\
\qquad(7 \mu \mathrm{m})\end{array}$ & micro & N/A & $<100$ & N/A & 26 & 100 & 0.9 & 1.3 \\
\hline Lin et al. ${ }^{13}$ & $\begin{array}{c}\text { 3D } \\
\text { Graphene/CNTs } \\
(10 \mu \mathrm{m})\end{array}$ & micro & $81.5^{\circ}$ & 1343 & 0.195 & 0.82 & 400 & 1.9 & 1 \\
\hline
\end{tabular}


Table S2. Electrochemical performance of conducting polymer micro-pseudocapacitors studied in the current work.

\begin{tabular}{|c|c|c|c|c|c|c|c|}
\hline Electrode & $\begin{array}{c}-\Phi @ \\
120 \mathrm{~Hz}\end{array}$ & $\begin{array}{c}\mathbf{f}\left(\mathbf{G}-45^{\circ}\right. \\
\mathrm{Hz}\end{array}$ & $\tau_{\mathrm{RC}}(\mathrm{ms})$ & $\begin{array}{c}\tau_{\mathrm{o}} \\
(\mathrm{ms})\end{array}$ & $\begin{array}{c}\mathrm{S}_{\max } \\
(\mathrm{V} / \mathrm{s})\end{array}$ & $\begin{array}{c}\mathbf{C}_{\mathrm{A}} \\
\left(\mathrm{mF} / \mathrm{cm}^{2}\right)\end{array}$ & $\begin{array}{l}\mathbf{C}_{\mathrm{V}} \\
\left(\mathbf{F} / \mathrm{cm}^{3}\right)\end{array}$ \\
\hline PANI & $60^{\circ}$ & 250 & 0.8 & 4 & 20 & 0.52 & 52 \\
\hline PPY & $65^{\circ}$ & 300 & 0.6 & 3 & 100 & 0.4 & 38 \\
\hline PEDOT & $80.5^{\circ}$ & 1050 & 0.21 & 1 & 1000 & 0.3 & 30 \\
\hline $\begin{array}{c}\text { 3D } \\
\text { PEDOT/Si }\end{array}$ & $60^{\circ}$ & 200 & 0.75 & 0.35 & 100 & 2.9 & $\mathrm{~N} / \mathrm{A}$ \\
\hline
\end{tabular}




\section{References}

1. Subramanian, P.; Clark, N.; Winther-Jensen, B.; MacFarlane, D.; Spiccia, L. Vapour-Phase Polymerization of Pyrrole and 3,4-Ethylenedioxythiophene using Iron (III) 2, 4, 6Trimethylbenzenesulfonate. Aust. J. Chem. 2009, 62, 133-139.

2. Yuan, L.; Yao, B.; Hu, B.; Huo, K.; Chen, W.; Zhou, J. Polypyrrole-Coated Paper for Flexible Solid-State Energy Storage. Energy Environ. Sci. 2013, 6, 470-476.

3. Hou, Y.; Zhang, L.; Chen, L.; Liu, P.; Hirata, A.; Chen, M., Raman Characterization of Pseudocapacitive Behavior of Polypyrrole on Nanoporous Gold. Phys. Chem. Chem. Phys. 2014, 16, 3523-3528.

4. Miller, J. R.; Outlaw, R.; Holloway, B., Graphene Double-Layer Capacitor with AC LineFiltering Performance. Science 2010, 329, 1637-1639.

5. $\quad \mathrm{Du}, \mathrm{C}$.; Pan, N., Supercapacitors using Carbon Nanotubes Films by Electrophoretic Deposition. $J$. Power Sources 2006, 160, 1487-1494.

6. Sheng, K.; Sun, Y.; Li, C.; Yuan, W.; Shi, G. Ultrahigh-Rate Supercapacitors based on Eletrochemically Reduced Graphene Oxide for Ac Line-Filtering. Sci. Rep. 2012, 2, 247.

7. Yoo, Y.; Kim, S.; Kim, B.; Kim, W., 2.5 V Compact Supercapacitors Based on Ultrathin Carbon Nanotube Films for AC Line Filtering. J. Mater. Chem. A 2015, 3, 11801-11806.

8. $\quad$ Wu, Z. S.; Liu, Z.; Parvez, K.; Feng, X.; Müllen, K. Ultrathin Printable Graphene Supercapacitors with AC Line-Filtering Performance. Adv. Mater. 2015, 27, 3669-3675.

9. El-Kady, M. F.; Kaner, R. B., Scalable Fabrication of Figh-Power Graphene MicroSupercapacitors for Flexible and On-Chip Energy Storage. Nat. commun. 2013, 4, 1475.

10. Pech, D.; Brunet, M.; Taberna, P.-L.; Simon, P.; Fabre, N.; Mesnilgrente, F.; Conédéra, V.; Durou, H. Elaboration of a Microstructured Inkjet-Printed Carbon Electrochemical Capacitor. J. Power Sources 2010, 195, 1266-1269.

11. Gao, W.; Singh, N.; Song, L.; Liu, Z.; Reddy, A. L. M.; Ci, L.; Vajtai, R.; Zhang, Q.; Wei, B.; Ajayan, P. M. Direct Laser Writing of Micro-Supercapacitors on Hydrated Graphite Oxide Films. Nat. Nanotechnol. 2011, 6, 496-500.

12. Pech, D.; Brunet, M.; Durou, H.; Huang, P.; Mochalin, V.; Gogotsi, Y.; Taberna, P.-L.; Simon, P., Ultrahigh-Power Micrometre-Sized Supercapacitors Based on Onion-Like Carbon. Nat. Nanotechnol. 2010, 5, 651-654.

13. Lin, J.; Zhang, C.; Yan, Z.; Zhu, Y.; Peng, Z.; Hauge, R. H.; Natelson, D.; Tour, J. M. 3dimensional Graphene Carbon Nanotube Carpet-Based Microsupercapacitors with High Electrochemical Performance. Nano lett. 2012, 13, 72-78. 